\title{
Retrospective Analysis Of 11,383 Patients Admitted To The Emergency Department With Head Trauma Within 2 Years
}

\author{
I B Atci, S Albayrak, E Durda, O Ayden, E G, N Yilmaz
}

\begin{abstract}
Citation
I B Atci, S Albayrak, E Durda, O Ayden, E G, N Yilmaz. Retrospective Analysis Of 11,383 Patients Admitted To The Emergency Department With Head Trauma Within 2 Years. The Internet Journal of Emergency Medicine. 2013 Volume 8 Number 1 .
\end{abstract}

DOI: $\underline{10.5580 / \mathrm{IJEM} .1477}$

\begin{abstract}
Traumas are one of the most common reasons of mortality and morbidity in the world. The WHO (World Health Organization) estimates that approximately 3.5 billion people die from the primary and secondary effects of a trauma every year $(1,2,3)$. At the present time, trauma is the first reason of mortality in younger ages, and is the third reason after cardiovascular disease and cancer in all age groups $(4,5)$.

Head trauma is one of the most important causes of increasing mortality and morbidity. The studies conducted in the US suggest that every year 200,000 patients die from head traumas. In the world traffic accidents are one of the most common reasons of head traumas $(5,6,7)$. In Turkey in patients with head trauma (adult and pediatric ages) the causes of the traumas are traffic accidents, falls and assault (65\%) (6-8). Traumas have high mortality and morbidity rates and economic burdens. But epidemiological studies about head traumas are rare and preventive medicine is required $(2,8,9)$.

In this study 11,383 patients who visited the Elazig Training and Research Hospital with head trauma were examined retrospectively.
\end{abstract}

\section{INTRODUCTION}

Traumas are one of the most common reasons of mortality and morbidity in the world. The WHO (World Health Organization) estimates that approximately 3.5 billion people die from the primary and secondary effects of a trauma every year $(1,2,3)$. At the present time, trauma is the first reason of mortality in younger ages, and is the third reason after cardiovascular disease and cancer in all age groups $(4,5)$.

Head trauma is one of the most important causes of increasing mortality and morbidity. The studies conducted in the US suggest that every year 200,000 patients die from head traumas. In the world traffic accidents are one of the most common reasons of head traumas $(5,6,7)$. In Turkey in patients with head trauma (adult and pediatric ages) the causes of the traumas are traffic accidents, falls and assault (65\%) (6-8). Traumas have high mortality and morbidity rates and economic burdens. But epidemiological studies about head traumas are rare and preventive medicine is required $(2,8,9)$.

In this study 11,383 patients who visited the Elazig Training and Research Hospital with head trauma were examined retrospectively.

\section{MATERIAL AND METHODS}

We included the patients who visited our emergency department with head trauma between 01.11.2010 and 01.11.2012 of ages up to 85. The patients were evaluated for age, gender, etiology, Glasgow Coma Scale, radiological findings, the results of treatment, surgical rates and mortality rates retrospectively. Head trauma was classified as mild (GCS 13-15), moderate (GCS 9-12), high (GCS 3-8). The hospitalization time and outcomes (hospitalization, discharge) were analyzed. The data of the patients who underwent surgery were collected. The patient's data were calculated as percent of average.

\section{RESULTS}

11,383 patients aged from newborn to 85 who visited to emergency ward with minor or major head trauma were included in this study. The cases were divided into two groups. Neurosurgery consultation was done or the patient was discharged by emergency specialist. Of the 11,383 cases 7398 were falls, 2959 were traffic accident, 1024 were 
assault (table 1). Especially during summer there is an increase at the patients who are up to 10 years old and who visit the emergency center due to falls. Traffic accidents were the first reason in adults. The patients' gender was generally male especially those who visited the emergency department with traffic accidents or falls from height. The most common age of the traumas was 10 to 35.7614 were male and 4199 were female. For 22\% (2400 patients) neurosurgery consultation was needed and 78\% (8983 patients) were discharged by an emergency specialist. Glasgow Coma Scale was 3-8 in 65 cases , 9-12 in 250 cases and 13-15 in 11,068 cases. (table 2)

\section{Table 1}

Patient demographics

\begin{tabular}{|l|l|l|}
\hline & Number & Percentages \\
\hline Falls & 8537 & 75 \\
\hline Traffic accident & 1821 & 16 \\
\hline Assault & 1024 & 9 \\
\hline
\end{tabular}

\section{Table 2}

Glasgow Coma Scale

\begin{tabular}{|l|l|l|l|}
\hline Glasgow Coma Scale & High(0-8) & Moderate(9-12) & Mild(13-15) \\
\hline & $0.5 \%, 65$ & $2.2 \%, 250$ & $87.3 \%, 11068$ \\
\hline
\end{tabular}

From 11,383 patients, CT was not performed in $19.9 \%$ (2276 patients). CT findings were normal in $76.3 \%$ (8657 cases), fractures were detected in $2.8 \%$ (326 cases). $2.7 \%$ (308 of these fractures) were linear and $0.1 \%$ (18 were depression). Intraparenchymal lesion was detected in $0.74 \%$ ( 85 cases), epidural hematoma in $0.13 \%$ (15 cases), subdural hematoma in $0.09 \%$ (11 cases), subarachnoid hemorrhage in $0.02 \%$ (23 cases), contusion in $0.029 \%$ (34 cases) and traumatic ICH in 2 cases.(table 4 )

Sixty-five patients who were consulted by a neurosurgeon were treated at the intensive care unit, $13.5 \%$ (325 patients) were treated at neurosurgery service. $83.8 \%$ (2100 patients) were followed up at the emergency ward and discharged with medical treatment. The mean hospitalization time was 1-20 days (mean 8) at 390 patients.(table 3)

\section{Table 3}

Patient data

\begin{tabular}{|l|l|}
\hline Gender & $\begin{array}{l}\text { Male: } 64.4 \%, 7614 \\
\text { Female:35.6\%,4199 }\end{array}$ \\
\hline Age & $0 / 85$ years old \\
\hline Neurosurgery consultation rate & $22 \%, 2400$ \\
\hline Surgery performed & $1.91 \%, 46$ \\
\hline Intensive care & $2.7 \%, 65$ \\
\hline Hospitalization and observation & $13.5 \%, 325$ \\
\hline Observation at emergency & $83.8 \%, 2100$ \\
\hline
\end{tabular}

\section{Table 4}

CT findings

\begin{tabular}{|l|l|}
\hline Normal & 8657 \\
\hline Linear fracture & 316 \\
\hline Depression fracture & 18 \\
\hline Subdural hematoma & 11 \\
\hline Epidural hematoma & 15 \\
\hline Subarachnoid hemonthage and contusion & 23 \\
\hline Contusion & 34 \\
\hline Diffuse axonal injury & 4 \\
\hline Traumatic cerebral edema & 36 \\
\hline Traumatic ICH & 2 \\
\hline TOTAL & 11,383 \\
\hline
\end{tabular}

After neurological examination at the emergency service, A$\mathrm{P}$ (anterior-posterior) and lateral $\mathrm{x}$-ray of the head and if necessary cervical x-ray, and thoraco-lumbar x-ray were performed. Patients with Glasgow Coma Scale: 13-15 and normal cranial x-ray were followed, and when Glasgow Coma Scale decreased, CT was performed. For a patient with Glasgow Coma Scale under 12 and fracture at cranial xray, a CT was performed routinely.

Surgery was performed because of depression fracture, epidural hematoma and subdural hematoma. Linear fractures, subgaleal pathologies, subarachnoid hemorrhage and cerebral edema were treated by medical treatment or by observation. Surgery was needed at $1.91 \%$ (46 patients). $28.6 \%$ (18 cases) of them were depression fracture, $21.4 \%$ (15 cases) were epidural hematoma, 11 were subdural hematoma and 2 were traumatic intracerebral hematoma. Mortality rate was $1.2 \%$.

\section{DISCUSSION}

With this study we aimed to add novel data to our epidemiological data in our country. At present, traumas and as a result, head traumas are common at the emergency center. Mortality, long hospitalization time and its social, psychological and economical effects are public health problems and this must be analyzed. Morbidity, long time rehabilitation and psychological support programmes increase the economic cost (5-10-11)

In our country, the most common causes of death from head traumas are traffic accident and falls from height (4-6-7). At early childhood, fall from height is the most common cause. In developed countries, traumas are the first cause of death (1-5-6). At epidemiological studies, head traumas are common in male gender. (12) In our study, 35.6\% (4199 cases) were female, $64.4 \%$ (7614 cases) were male and the male/female rate was 1.81 . These results correlated with the literature.

Ötken at al. (13) showed that $83.3 \%$ of the cases had mild head trauma, $6.8 \%$ had moderate and $9.9 \%$ had a heavy head 
trauma. Murgio at al. (14) made two studies and the rates were $56.4 \%, 38.9 \%, 4.7 \%$ in the first study and $79.1 \%, 18 \%$ , $2.9 \%$ in the second study respectively. In our study these rates were $87.3 \%, 2.2 \%$ and $0.5 \%$ respectively. Our findings did not correlate with previous studies.

The reason of low rates of mild head traumas is that our hospital is sited at the city center, neighbour to another state hospital and university hospital. And also patients with heavy head trauma are usually dispatched to the university hospital.

Falls take the first place at the etiologic reasons of the head traumas. The second is traffic accident and assault is third.(12) At our study falls were at the first place and this correlated with the literature.

CT is gold standard at evaluation of the patients with head traumas at the emergency center. (15) The indications are still controversial. Because of the intense workload at the emergency wards, neurological examination cannot be made exactly. Sometimes CT is performed before routine X-ray and neurological examination. And these unnecessary tests affect the hospital and states economy adversely. In our study, CT request rate was $76 \%$ and pathological findings were detected at $4 \%$. As a result our CT request rate was high. The reasons of these high rates are the high intensity of the workload at emergency wards, inexact neurological examination and fear of our doctors about misdiagnosis. In addition, courses about $\mathrm{CT}$ indications should be useful. Forty six $(1.91 \%)$ patients underwent surgery. The first indication of the surgery was depression fracture. The second was subdural hematoma. At Yuceer et all's study the surgery rate was $11.3 \%$ and the most common cause was epidural hematoma $(50 \%)(16)$. In another study that was made at our country the operation rate was $10.5 \%$ and the most common causes were depression fracture and epidural hematoma (12). Compared to the literature review, our surgery rate was low. The causes of this condition are, included age groups to this study, two state hospital and university hospital's neighborhood status and the choice of 112 emergency services in the university hospital.

In this study, hospitalized $385(98.8 \%)$ patients were treated and $5(1.2 \%)$ patients died.

\section{CONCLUSION}

In our region the most common causes of head traumas are traffic accidents and falls. Especially in summer, falls are at the first place in childhood and traffic accidents rank first in adults.

To decrease the mortality and morbidity of head traumas, constructing family and community awareness and taking protective measures before traumas are needed. After trauma, a full-fledged intensive care and qualified staff is important.(1-5-11)

As it is a public health problem, education at early childhood and compliance with the traffic rules should decrease the head traumas and economic burden.

\section{References}

1. Binder S, Corrigan JD, Langlois JA: The public health approach

to traumatic brain injury: An overview of CDC's research and

programs. J Head Trauma Rehabil 20:189-195,2005

2. Jennett B: Epidemiology of head injury. J Neurol

Neurosurg

Psychiatry 60:362-369,1996

3. Peden M, McGee K, Sharma G: The injury chart book: A graphical overview of the global burden of injuries, Geneva: World Health Organization, 2002

4. Ç?rak B, Berker M, Özcan OE, Özgen T: Kafa travmalar?n?n

etken ve sonuçlar?na bir bak??: Epidemiyolojik bir çal??ma. Ulus Travma Derg 5:90-92,1999

5. Langlois JA, Rutland-Brown W, Wald MM: The epidemiology

and impact of traumatic brain injury: A brief overview. J

Head

Trauma Rehabil 21:375-378, 2006

6. K?r?? T, ?? M, ?mer M, Güleç ?, Ünal F, ?zgi N:

Nöro?irurjide travma

prati?i, prospektif epidemiyolojik çal??ma. Ulus Travma

Derg 4:281-284,1998

7. Markogiannakis H, Sanidas E, Messaris E, Koutentakis D, Alpantaki K, Kafetzakis A, Tsiftsis D: Predictors of inhospital

mortality of trauma patients injured in vehicle accidents. Ulus

Travma Acil Cerrahi Derg 14:125-131,2008

8. Karasu A, Sabanci PA, Cansever T, Hepgul KT, Imer M, Dola?

I, Tavilo?lu K: Epidemiological study in head injury patients.

Ulus Travma Acil Cerrahi Derg 15:159-163,2009

9. Akkose S, Arma?an E, Bulut M, Tokyay R: Trauma care system

in Turkey and the approach to patients suffering head trauma.

Ulus Travma Derg 8:1-2, 2002

10. Stranjalis G, Bouras T, Korfias S, Andrianakis I, Pitaridis M,

Tsamandouraki K, Alamanos Y, Sakas DE, Marmarou A:

Outcome in 1,000 head injury hospital admissions: The

Athens head trauma registry. J Trauma 65:789-793, 2008

11. Thurman DJ, Alverson C, Dunn KA, Guerrero J, Sniezek JE:

Traumatic brain injury in the United States: A public health 
perspective. J Head Trauma Rehabil 14:602-615,1999

12. I??k H, Gokyar A, Y?ld?z O, Bostanc? U, Ozdemir C. Pediatric head injuries,

retrospective analysis of 851 patients: an epidemiological study. Ulus

Travma Acil Cerrahi Derg 17: 166-72, 2011

13. Okten A, Yalman M, Kapalano?lu E, ve ark. Pediatrik kafa travmalar?.

Ulusal Travma Dergisi 2: 94-9, 1996

14. Murgio A, Andrade FA, Sanchez Munoz MA, Boetto S, Leung KM.
International Multicenter Study of Head Injury in Children. ISHIP Group.

Childs Nerv Syst 15: 318-21, 1999

15. Teasdale G, Teasdale E, Hadley D. Computed tomographic and magnetic

resonance imaging classification of head injury. J

Neurotrauma 9

Suppl 1:S249-57, 1992

16. Yuceer N, Mertol T, Arda M. Kafa travmal? 106 cocuk olgunun klinik de?erlendirme

sonuclar?. Du?unen Adam 18: 95-100 , 2005 


\section{Author Information}

\section{Ibrahim Burak Atci}

Department of Neurosurgery, Elaz?? Training and Research Hospital Elaz??, Turkey

drburakatci@hotmail.com

\section{Serdal Albayrak}

Department of Neurosurgery, Elaz?? Training and Research Hospital Elaz??, Turkey

\section{Emre Durda}

Department of Neurosurgery, Elaz?? Training and Research Hospital Elaz??, Turkey

\section{Omer Ayden}

Department of Neurosurgery, Elaz?? Training and Research Hospital Elaz??, Turkey

\section{Evrim G}

Department of Emergency, Elaz?? Training and Research Hospital Elaz??, Turkey

\section{Nejat Yilmaz}

Department of Neurosurgery, Elaz?? Training and Research Hospital Elaz??, Turkey 